\title{
OBSERVATIONS ON THE DESCENT OF THE TESTICLE WITH SPECIAL REFERENCE TO SPONTANEOUS DESCENT AT PUBERTY
}

\author{
BY \\ R. E. SMITH, M.A., M.B., M.R.C.P. \\ Medical Officer to Rugby and Lawrence Sheriff Schools and Physician \\ to the Hospital of St. Cross, Rugby.
}

The testicle is normally in the scrotum at birth, but its descent may be arrested at any point from its origin near the kidney to its final destination. The majority of so-called undescended testicles should be described as partially descended testicles. At the present time, surgery and endocrine therapy are active lines of treatment. However, there is an increasing tendency to trust to spontaneous descent at puberty, and the object of this paper is to justify that policy in particular cases.

\section{Previous reports of spontaneous descent}

In 1918, H. G. Armstrong, Medical Officer to Wellington College, Berkshire, wrote in the Guy's Hospital Gazette that during the previous seven years, seven boys among approximately one thousand new entrants were found to have complete absence of both testicles from the scrotum. All seven had small genitalia ; the scrotum resembled a small piece of wrinkled skin ; pubic hairs were absent. Four had rarefaction of the outer third of the eyebrows and one was of a Mongolian type. Three suffered from nocturnal enuresis. All were given half a grain of thyroid extract twice daily over a considerable period. In six the testicles descended, but in the seventh the left testicle entered the scrotum, the right the perineum. By the end of adolescence the testes and genitalia grew to normal size, although some of the boys had only scanty pubic hair. He never had the same success with a single undescended testicle. Whether or not the thyroid was responsible or whether or not the descent would have occurred spontaneously at puberty cannot be definitely decided, but the subsequent evidence will point to the probability of spontaneous descent.

Although Bjerre only published his figures in 1937, his researches on 251 cryptorchids date back to 1900 . Of these 196 were operated on between 19001930 and the testicle fixed in the scrotum. Many had passed puberty, but the average age at operation was twelve. The results were good in fifty-eight, bad in thirty-two and followed by atrophy in ten per cent. The further the testicle had descended in its course from the abdomen, the better were the results. A six months' interval was allowed to elapse between the operations for bilateral non-descent. For a large series dating from 1900 these figures compare not unfavourably with the successes of other surgeons. Bjerre compared these 
196 cases with a control series of 188 boys composed of the fifty-five unoperated cases added to 133 boys in a school where the medical authorities disapproved of operation. One hundred and nineteen (sixty-three per cent.) of these descended spontaneously and the school statistics showed that descent nearly always occurred about the age of fifteen. In the other group accurate information was not available.

Drake has reported spontaneous descent in twenty-four of thirty-eight cases at ages ranging from ten to sixteen.

Williams observed 2,104 boys, in whom spontaneous descent occurred in twenty-four (sixty-three per cent.) of thirty-eight unilaterally undescended testicles, and in fourteen (sixty-seven per cent.) of twenty-one bilaterally undescended testicles. Ten boys were not seen for a sufficient time for adequate observation, and six boys had a hernial sac or a previous operation for one. Omitting these boys, Williams found that descent took place in twenty-four of the twenty-seven unilateral (eighty-nine per cent.), and in fourteen of the sixteen bilateral, (eighty-seven per cent.), and that the age of descent was as follows :

$\begin{array}{lllllc}\text { AGE OF DESCENT } & & & \text { UNILATERAL } & \text { BILATERAL } \\ 11-12 \text { years } & \ldots & \ldots & \ldots & 2 & 2 \\ 12-13 \quad,, & \ldots & \ldots & \ldots & 5 & 3 \\ 13-14 \quad, & \ldots & \ldots & \ldots & 4 & 1 \\ 14-15 \quad, & \ldots & \ldots & \ldots & 7 & 5 \\ 15-16 \quad, & \ldots & \ldots & \ldots & 5 & 3 \\ 16-17 \quad,, & \ldots & \ldots & \ldots & 1 & 1\end{array}$

\section{Treatment with gonadotropic hormones}

Bigler, Hardy and Scott (1938a) have recently summarized eighteen reports of the hormonal treatment of undescended testicles. The dosage varied considerably, e.g. in Spence and Scowen's series (1935), 500 rat units were given intramuscularly routinely twice a week for an average of four months, but the limits were two weeks and fourteen and a half months. The preparations used by the eighteen were extract of anterior lobe of hypophysis, either obtained directly or from the urine of pregnant women, and follutein, or a combination of these. Proprietary names of the preparations are often used. Of the 267 undescended testicles treated, 176 (sixty-five per cent.) completely descended.

Spence and Scowen (1938) have brought their experiences up to date. They find all retractile testes will respond to hormone therapy, that in their series of seventeen bilaterally and eleven unilaterally undescended testicles situated in the inguinal canal which could not be manipulated into the scrotum, seventy-six per cent. of the bilateral and sixty-four per cent. of the unilateral group responded to hormone therapy, whereas a successful result was not likely to occur if the testicle were not palpable.

Bigler and his fellow workers (1938b) in an investigation designed to test the value of hormone therapy were unable to get such high percentages of successes, even in cases in which they were satisfied that the dosage was adequate. Of thirty-one undescended testicles in twenty-three patients treated with antuitrin-S, fourteen (forty-five per cent.) remained undescended ; one failed to remain descended : of forty undescended testes in thirty-two patients treated with gonadotropic hormone obtained from the urine of pregnant women, ten (twenty-five per cent.) completely descended into the scrotum, but only seven remained there : and of twenty undescended testicles in sixteen patients treated with a mixture of both, eight (forty per cent.) showed complete descent but only five (twenty-five per cent.) remained descended. They believe that if a testicle is going to descend, it will do so before 4,000 rat units have been given. 


\section{Results of surgical treatment}

Bigler and his co-workers (1938a) have also reviewed the surgical aspect. They found from a study of the literature up to 1922 that operation was a failure in fifty per cent. of cases ; that American surgeons reported 'cures' ranging from forty-two to ninety-two per cent. In America two operations are in vogue : the Bevan operation, probably the more popular, consists of mobilizing the testicle and after elongation of the cord suturing the testicle to the lowest part of the scrotum, and Torek's operation, which is becoming more popular and consists of freeing the testicle and suturing it to the fascia of the upper part of the thigh ; after three to six months the testes and scrotum are dissected from the thigh.

In England a third type of operation is often performed. This consists of anchoring the freed testicle in the scrotum by pushing it through a hole made in the scrotal septum. Turner, who usually practises this method, sums up his experience of fifty patients as follows :

COMPLETE SUCCESS : Testicle hangs normally and easily and is well in scrotum $\quad \ldots \quad \ldots \quad \ldots \quad 35$, i.e., 70 per cent.

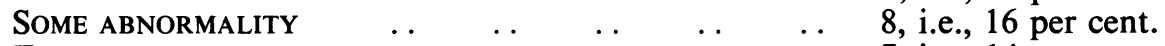

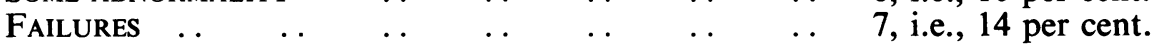

\section{Object of present investigation}

It will be agreed that each of the three methods of treatment has a creditably high percentage of cures. My interest in this problem started in 1930, when I was appointed medical officer to two schools, one with approximately six hundred boys from thirteen to eighteen years of age, and one of four hundred from nine to eighteen years. Schapiro published his findings in September, 1930, but I was not aware of them until 1935, when Spence and Scowen published their paper, and my object was to study the natural history of the late descent as a biological problem, especially to determine if operation was always necessary, as was generally taught and practised in my own medical school. Other interesting facts arose from my observations, as detailed notes below show.

Case 1. Undescended Testicles. Pluriglandular Dystrophy. Descent When Aged 16 after taking Testicular Extract.

In 1929, a stunted boy of thirteen years and nine months on admission to school weighed $102 \mathrm{lb}$. and was 55 inches high, compared with normal of $96 \mathrm{lb}$. and 61 inches. In May, 1932, he weighed $124 \mathrm{lb}$. and was 59 inches high. His facial expression was that of an adult, but his mental attitude was that of a child some years younger than his age. From 1929-1932 he took half a grain of extract of dry thyroid and two grains of extract of whole pituitary gland. These were omitted in May, 1932, and by November, 1932, he had grown two and a half inches and put on only nine pounds; his mental capacity had increased. The chief concern of his parents was the failure of the testicles to descend. In March, 1932, he was given forty minims Orchitogene (Marogliano) night and morning and by June of that year his testicles became fully descended and remained so, although he took no more of this preparation. This boy was referred by my predecessor Dr. A. I. Simey to Sir Walter Langdon Brown, who prescribed the various endocrine preparations for him, and his help is gratefully acknowledged. Whether or not the descent was 'post' or 'propter' the orchitogene, it is not possible to say. 
Case 2. Bilateral Undescended Testicles. Spontaneous Descent, Right at 13 Years, Left at 13 Years 10 Months. Normal Development. Operation for Left Inguinal Hernia at Age 2 Years.

A boy born in December, 1921, was first seen by me in May, 1933. Both testicles were undescended. In July, 1934, the right testicle could be made to descend, but not the left. In May, 1935, both testicles were in scrotum. He was then aged thirteen years and ten months. In December, 1935, both testicles were still in the scrotum. The penis was still small, and the boy fat, especially his abdomen and breasts. In June, 1936, the testicles were the size of marbles, and in June, 1937, were of normal size. Puberty was by then well advanced. At the age of two years he had an operation for a left inguinal hernia, which apparently was completely successful. He had been seen in September, 1929, at the age of eight, by Dr. Simey, who had also noted that both testicles were undescended.

Case 3. Bilateral Undescended Testicles. Generalized Obesity. Right Testicle Brought into Scrotum and Fixed by Transplantation through the Septum. Descent of Left Testicle Spontaneously at age $13 \frac{3}{4}$ YeARS.

This boy was first seen in October, 1935, when he was eleven years and three months of age. His height was $59 \frac{1}{8}$ inches, weight $96 \frac{1}{2} \mathrm{lb}$. The obesity was generalized. Both testicles were situated in the mid-inguinal region. In May, 1936, the right testicle was palpable above the external inguinal ring ; the left was not palpable. In December, 1936, the right testicle was operated on ; it was easily brought down into the scrotum and was put through a hole in the septum into the contra-lateral half of the scrotum. When the boy was seen in June, 1937, the testicle was of apparently normal size. No change was noted in January, 1938. In March, 1938, the boy noticed that the left testicle had fully descended and both are of equal and of good size in the left half of the scrotum. In October, 1938, puberty was just starting.

Case 4. Bilateral Undescended Testicles. Generalized Obesity. Spontaneous Descent at Age $13 \frac{3}{4}$ Years.

A boy aged thirteen and a half entered school in September, 1936. His

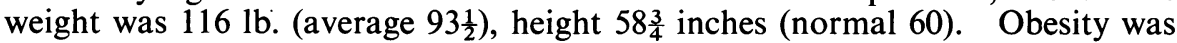
generalized. Neither testicle had descended. The scrotum was flat against the perineum. By December, 1936, both testicles had descended ; the boy himself had noted this. In February, 1937, I was able to palpate both testicles in the scrotum, which was considerably flattened. His weight was $113 \frac{1}{2} \mathrm{lb}$. and his height 59 inches. In October, 1938, both testicles were in the scrotum, which had become a pouch. The pubic hair was scanty.

Case 5. Bilateral Undescended Testicles. Infantile Scrotum. SPONTANeOUS Descent at $13 \frac{1}{2}$ Years.

This boy was first seen in October, 1933, aged eight years and four months. His height was $52 \frac{1}{4}$ inches, weight $62 \frac{1}{2} \mathrm{lb}$. In June, 1936, at the age of eleven, both testicles were undescended. In December, 1936, the scrotum was not yet a bag, and neither testicle was palpable. In June, 1937, at the age of twelve, both testicles were in the scrotum, and were of good size ; the penis was growing, and the scrotum was a definite bag. The boy's height was 59 inches and he weighed $80 \mathrm{lb}$. In October, 1938, the testicles had developed, although pubic hair was still very scanty. 
Case 6. Bilateral Undescended Testicles. Descent at Puberty.

This boy was first seen in November, 1935, aged twelve and a half years. His height was $58 \frac{1}{4}$ inches, weight $94 \frac{1}{2} \mathrm{lb}$. There was no abnormality except that neither testicle was in the scrotum. He had never noticed them. Pubic hairs were just appearing. In June, 1936, pubic hairs were half an inch long ; both testicles were in the scrotum, and were the size of lentils. In December, 1936, both testicles were well in the scrotum and many pubic hairs were present. In June, 1937, both testicles were as large as nutmegs, and pubic hairs numerous. The penis was of normal size. The boy was then $61 \frac{1}{2}$ inches tall and weighed $109 \mathrm{lb}$. He was seen again in October, 1938, when both testicles had grown to normal size.

Case 7. Bilateral Undescended Testicles. Right Descended at $14 \frac{1}{2}$ Years. Left Descended at 15 Years.

The patient was born in February, 1923 ; when first examined in November, 1935 , his height was $56 \frac{1}{4}$ inches and weight $76 \frac{1}{2} \mathrm{lb}$. ; neither testicle could be felt in the scrotum or inguinal canal. When re-examined in June, 1936, and again in December, 1936, testicles were not palpable and puberty had not started. In June, 1937, the right testicle was in the scrotum and the left just outside external inguinal ring. Testicular sensation was normal. Puberty had not started. In January, 1938, both testicles had completely descended, and puberty was starting. In October, 1938, both testicles were equal and of good size, and puberty well advanced.

Case 8. Bilateral Undescended Testicles. Both in Inguinal Canal. Puberty Advanced. Patient $15 \frac{1}{2}$ Years.

Born in May, 1922, the patient was first seen in February, 1935. Both testicles were then high up in the inguinal canal. In June, 1935, there was no change; testicular sensation was normal. When examined in December, 1935, and June, 1936, both testicles were half-way down the inguinal canal ; pubic hairs were plentiful. In June, 1937, both testicles were situated at the upper end of the inguinal canal and puberty was advancing. Examination in January and October, 1938, showed no change. Sensation in both testicles was normal. The patient's present height is $61 \frac{5}{8}$ inches and weight $78 \mathrm{lb}$.

Case 9. Bilateral Undescended Testicles. Descent of Left at Age $11 \frac{1}{4}$ Years. Right STILl UNDESCENDEd Age $12 \frac{1}{4}$ Years.

Patient was born in February, 1924, and was first seen in January, 1935. His height was then $56 \frac{1}{2}$ inches and weight $75 \frac{1}{2} \mathrm{lb}$. Both testicles were half-way down the inguinal canal. In July, 1935, the left testicle was in the scrotum, and the right in the inguinal canal. A few pubic hairs were present. In December, 1935, there was no change. In June, 1936, sparse pubic hairs had appeared. The right testicle was still half-way down the inguinal canal. (He has now left the neighbourhood, and further follow-up is impossible.)

Case 10. Undescended Right Testicle. Spontaneous Descent at Age of 14 Years. Late Puberty.

A boy aged thirteen and a half, a scholar of average build, entered school in September, 1934. The right testicle was half-way down the inguinal canal and had normal sensation. The blood pressure was $95 / 65$. On November 21 st, 1934, there was no change, but on December 18th, 1934, the testicle had descended completely into the scrotum and was as large as its fellow. Puberty had not started. In February, 1935, the condition was as before. In May, 1935, the boy was fourteen ; the testicle was now completely in the scrotum. 
Case 11. Right Undescended Testicle. Still Undescended AlThough Puberty is Advanced and Patient is 17 Years.

Patient was born in September, 1921. In July, 1935, the left testicle was found to be the size of a bantam's egg and in the scrotum ; the right was small and in the inguinal canal. The boy's intelligence was normal. In December, 1935, there was little change ; puberty was starting. In June, 1936, the right testicle was the size of a kidney bean and at the external inguinal ring. Sensation was normal, and puberty was well advanced. In December, 1936, there was no change, and puberty was far advanced. In June, 1937, the right testicle was still in the inguinal canal. Re-examined in December, 1937, and October, 1938 , there was no change ; the testicle was still the size of a kidney bean and palpable at the external inguinal ring.

Case 12. Right Undescended Testicle - Operation. Atrophic Testicle Removed.

A boy entered school in May, 1931, aged thirteen years nine months. The right testicle was still in the inguinal canal and would not descend. Puberty had not started. His weight was $98 \mathrm{lb}$. and height 63 inches. Operation was advised to try to get the testicle to come down into the scrotum, and though the father was opposed to this, he had it performed in September, 1932, by Mr. Frank Barnes. At operation, the testicle was found to be so atrophic that the only course was total removal. This made no difference to the boy's physical development, and he later won a scholarship at Oxford.

Case 13. Undescended Left Testicle. Puberty Advanced. Testicle IMPALPABLE AT AGE OF $13 \frac{1}{2}$ Years.

Born in 1925, the boy was seen in October, 1933, when his weight was $55 \frac{1}{2} \mathrm{lb}$. and height $51 \frac{1}{8}$ inches, and in June, 1936 his weight was $73 \mathrm{lb}$. and height $56 \frac{5}{8}$ inches. The left testicle was undescended. In December, 1936, the left testicle was impalpable. Pubic hair was appearing. In June, 1937, the condition of the left testicle was unchanged. The penis was large, and the right testicle the size of a pigeon's egg. In October, 1938, the left testicle was still not palpable, although puberty was far advanced.

Case 14. Undescended Right Testicle. EnLARgement BUt NOT Descent with Pregnyl. Operation on Ectopic Testicle, which was FIXED IN SCROTUM.

This boy entered school in September, 1933, at the age of thirteen years and eight months. His right testicle was undescended and puberty was advanced. In May, 1936, when the boy was sixteen, it was decided to try to get the testicle to descend with pregnyl. He was given two courses of twelve injections with 500 rat units from May to September, 1936, and a further twelve injections from October to December, 1936. This had the effect of causing the testicle to enlarge considerably. He was given a further course from January to March, 1937, and although the testicle, which was originally no bigger than a pea, had increased to more than twice this size, it would not come down any further than just below the internal inguinal ring. He had been seen in consultation with Sir Walter Langdon Brown on two occasions, and on the third occasion, in April, 1937, it was decided that the testicle was probably mechanically prevented from descending and operation was advised. This was performed by Mr. W. D. Doherty on May 1, 1937. The testicle was found to be of considerably larger size than was expected from manual palpation and to have ridden over the anterior border of the internal inguinal ring. 
With considerable difficulty the testicle was brought down into the scrotum and fixed there by transposition through the septum. Six weeks later, it was still in position, and was rapidly approaching the size of its fellow. He has been given one more course of pregnyl injections with beneficial results.

Case 15. Undescended Testicle. Puberty Advanced. Attempt to Make Testicle Descend with Pregnyl. Successful Operation.

A boy entered school in January, 1937, aged thirteen and a half years. His height was $64 \frac{1}{2}$ inches (average 60 inches), and his weight $134 \mathrm{lb}$. (average $93 \frac{1}{2}$ lb.). The right testicle was found at the upper end of the inguinal canal. Puberty was advanced. He was over weight, even allowing for his height. $\mathrm{He}$ was given a course of twelve injections of pregnyl, at bi-weekly intervals, of 500 rat units. On March 10, the testicle was half-way down the inguinal canal. Between February and December, 1937, he had four courses of twelve injections of pregnyl (500 units bi-weekly) with approximately a month's rest between each course. The testicle did not descend, but steadily increased in size. In December, 1937, he was operated on by Mr. L. R. Braithwaite, who wrote : - The condition of the testis was one of ascent and not the usual kind of undescent. The testis had left the external ring, as you described, and had turned completely upwards, so that the lower pole was pointing towards the right shoulder. It was, therefore, a very easy matter to turn it down and get it into the upper part of the scrotum, and this was done without any division of anything else. I am quite sure, though it may be rather high in the scrotum for a while, that it will descend perfectly well.'

He was given one more course of twelve injections of pregnyl and the testicle fully descended and was equal to its fellow.

Case 16. Right Undescended Testicle. Spontaneous Descent.

A boy, when aged eleven, in 1932 was under observation at Alton by Sir Henry Gauvain, who noticed that the right testicle was undescended and could not be felt in the inguinal canal. In September, 1935, when he entered school, and on two subsequent occasions, his testicle was found to be in the scrotum. On entry he was $16 \mathrm{lb}$. and $1 \frac{1}{4}$ inches under average weight and height.

Case 17. Undescended left Testicle. Descent at Age 14 Years, 8 Months before Puberty. Late Eruption of Teeth.

A boy aged thirteen years eight months entered school in September, 1935. The left testicle could be pushed down as far as the external ring. Sensation was normal. He was examined at intervals, but no change occurred until September, 1936, when the testicle descended fully into the scrotum. There was no sign of puberty. All his teeth were late in erupting, especially his canines, which erupted in his fifteenth year, i.e. two years later than normal. The association of the late eruption of the canines and the late descent of the testicles has been noted by Marvin. I have looked for this carefully in all my cases of undescended testicles, but this is the only one in which I have seen the connexion.

Case 18. Spontaneous Descent of Testicle at Age $13 \frac{1}{2}$ Years.

A boy came with a note from his doctor to say he had an undescended testicle, which was going to be operated on before entering school. However, during the holidays it started to descend and by the beginning of term, when he was thirteen years and nine months, it was normally in the scrotum. Puberty was in progress. 
Case 19. Undescended Right Testicle. Descent at Age of $13 \frac{1}{4}$ Years. Testicle Smaller than its fellow. Cause of Delayed Descent Possibly MeChANICAL.

Born in March, 1920, the boy was first seen in May, 1933. His height was $58 \frac{1}{2}$ inches, and weight was $82 \mathrm{lb}$. The right testicle, which appeared normal in size, was lying at the lower end of the inguinal canal, but could be pushed just into the scrotum. In June, 1933, while in camp, he stretched out vigorously. This gave him acute pain in the inguinal region, and he noticed after this that his testicle had come down. I saw him again in November, 1933. Puberty was just starting. The right testicle was half the size of its fellow. In February, 1935, there was no change. Sensation was normal. In December, 1935 , pubic hair was abundant. The right testicle was two-thirds the size of the left, but both were large. He left school in 1936. It is difficult to explain the exact sequence of events. It is possible that the testicle was prevented mechanically from entering the scrotum, perhaps by an adhesion in the inguinal canal, too small an external inguinal ring, or that the testicle was anterior to the canal. The sudden movement might have overcome any one of these three factors. Another interesting feature is the development of the testicle after it descended.

Case 20. Undescended Left Testicle. Descent as far as Inguinal Canal. Puberty Advanced at Age of $13 \frac{1}{2}$ Years.

Born in December, 1923, the boy was seen in September, 1932, November, 1933, and July, 1935. The left testicle was undescended. There was steady increase in height and weight from $54 \frac{5}{8}$ inches and $67 \frac{1}{2} \mathrm{lb}$. to $64 \frac{1}{2}$ inches and 114 lb. in June, 1937. In November, 1933, he had tonsillar glands removed for a mild tuberculous infection. His intelligence was well up to the average. In December, 1935, there was no change in the testicle, and in June, 1936, the left testicle was still impalpable. In December, 1936, the left testicle was felt at the top of the inguinal canal and was the size of a pea. Puberty was advancing. In June, 1937, puberty was well advanced ; left testicle was still at the top of the inguinal canal. The patient has left the district, and further observation has not been possible.

Case 21. Right Undescended Testicle and Inguinal Hernia. Operation Aged 3 Years. Cure of Hernia. Testicle Half the Size of its Fellow and in Inguinal Canal.

A boy born November 15, 1923, was operated on when aged three years for a right inguinal hernia and undescended testicle. The operation for hernia was successful, but when examined in September, 1935, the right testicle, which was half the size of the left, was still in the inguinal canal. His height then was $55 \frac{1}{4}$ inches, and his weight $69 \mathrm{lb}$. He has been seen in June, 1936, December, 1936, and June, 1937. His physical condition was the same and there were no signs of puberty. In October, 1938, the testicle was at the lower end of the inguinal canal, was freely movable, and half the size of its fellow.

Case 22. Right Inguinal Hernia and Undescended Testis Which Remains at External Inguinal Ring at Age of $14 \frac{1}{2}$ Years.

Born in March, 1923, the boy was first seen in October, 1934. His height was 58 inches, and weight $76 \mathrm{lb}$., which had increased to $62 \frac{1}{2}$ inches and $100 \mathrm{lb}$. in June, 1937. In October, 1934, aged eleven and a half years, the right testicle was half way down inguinal canal. In December, 1935, and on each re-examina- 
tion up to June, 1937 (at age of fourteen and a half) the right testicle was at the external inguinal ring and no pubic hairs were present. He had a large right inguinal hernia which was constantly present in the inguinal canal. In October, 1938, the hernia was still present and the testicle could be felt with difficulty inside it.

Case 23. Right Undescended Testicle and Inguinal Hernia. Puberty Advanced. Operation for Hernia. Testicle Remains at External INGUINAL RING.

A boy born in October, 1922, was first seen in March, 1934. His height was then $57 \frac{1}{4}$ inches and weight $79 \frac{1}{2} \mathrm{lb}$., increasing to 66 inches and $127 \mathrm{lb}$. in June, 1937. His intelligence was just below the average. In March, 1934, a right inguinal hernia was present. This was easily reduced. The right testicle did not descend. Puberty was starting. In June, 1936, he had recently had an operation for right inguinal hernia. The testicle was then at the external inguinal ring, was the size of a pea, and half the size of its fellow. (Throughout this paper sizes are compared by the apparent length of the testicle from pole to pole and width from side to side. A testicle the axes of which are twice that of its fellow is approximately eight times its volume.) In December, 1936, there was no change, but puberty was far advanced. In June, 1937, there was no change. He has now left school, and further observations are unobtainable.

Case 24. Undescended Right Testicle. Unsuccessful Operation at Age of 9 Years. Failure to Induce Descent with Pregnyl.

A boy had an operation on his right testicle in 1932, when he was aged nine years. The attempt to bring down the testicle was unsuccessful. He was first seen in May, 1936. His mother was anxious to do everything she could for the boy, and agreed that he should have a course of injections of pregnyl. He was given five hundred rat units twice a week, commencing in June, 1936, and was given twenty-four injections in June, July, and August. At first there was a slight response, in that the testicle enlarged slightly to the size of a small pea ; but despite the fact that he was given two further courses of twelve injections of the same strength, the testicle failed to enlarge further or to descend, and in May, 1937, it was decided that it was no longer feasible to continue the injections.

\section{Discussion}

An analysis of these twenty-four cases will show that there are coincident factors associated with the original failure to descend, which give a clue to the ultimate prognosis.

Age incidence of undescended testicle.-In a school, the constant addition to and subtraction from its members makes it almost impossible to work out accurately the age-incidence. The table below is given with the knowledge that the experimental error is bound to be large ; but nevertheless it is significant that none of the 418 boys from sixteen to twenty had an undescended testicle. Case 14 was operated on on May 1, 1937. It is true there was none between eight and twelve, but this group only numbers 55 . The majority are in the age-group of twelve to sixteen.

As those with an associated hernia or previous operation for a hernia have a completely different prognosis, it is wise to consider the group without hernia separately, and this is shown in the last column. The same criticism about the groups over fifteen and under twelve still holds good. 


\begin{tabular}{|c|c|c|c|c|c|c|c|}
\hline \multirow{2}{*}{$\begin{array}{l}\text { AGE } \\
\text { IN } \\
\text { YEARS }\end{array}$} & \multirow{2}{*}{\begin{tabular}{|l} 
NUMBER IN \\
BOTH SCHOOLS \\
ON JUNE 1, \\
1937
\end{tabular}} & \multirow{2}{*}{$\begin{array}{l}\text { BOYS WHO HAD } \\
\text { UNDESCENDED } \\
\text { TESTICLES WHEN } \\
\text { FIRST OBSERVED } \\
\text { (CASE NO. IN } \\
\text { SERIES) }\end{array}$} & \multicolumn{3}{|c|}{$\begin{array}{c}\text { BOYS WITH UNDESCENDED } \\
\text { TESTICLES ON JUNE } 1 \text {, } \\
1937\end{array}$} & \multicolumn{2}{|c|}{$\begin{array}{c}\text { BOYS WITH UN- } \\
\text { DESCENDED } \\
\text { TESTICLES WITHOUT } \\
\text { ASSOCIATED } \\
\text { HERNIA ON JUNE 1, } \\
1937\end{array}$} \\
\hline & & & No. & $\begin{array}{c}\text { CASE NO. } \\
\text { IN } \\
\text { SERIES }\end{array}$ & $\begin{array}{l}\text { PERCENTAGE } \\
\text { IN AGE } \\
\text { GROUP }\end{array}$ & No. & $\begin{array}{l}\text { PERCENTAGE } \\
\text { IN AGE } \\
\text { GROUP }\end{array}$ \\
\hline $\begin{array}{l}19-20 \\
18 \\
17 \\
16 \\
15\end{array}$ & $\begin{array}{r}2 \\
63 \\
157 \\
196 \\
185\end{array}$ & $\begin{array}{c}\overline{-} \\
\overline{14} \\
10 \\
2,7,8,11,16\end{array}$ & $\begin{array}{c}- \\
\bar{z} \\
4\end{array}$ & $\begin{array}{c}\bar{z} \\
\bar{z} \\
7,8,11\end{array}$ & $\begin{array}{l}\overline{-} \\
\bar{z} \\
2 \cdot 2\end{array}$ & $\frac{\bar{E}}{\bar{z}}$ & $\begin{array}{l}\bar{Z} \\
\overline{1} \\
1 \cdot 6\end{array}$ \\
\hline $\begin{array}{l}14 \\
13 \\
12 \\
11 \\
10 \\
9 \\
8-9\end{array}$ & $\begin{array}{r}187 \\
76 \\
63 \\
31 \\
12 \\
10 \\
2\end{array}$ & $\begin{array}{c}4,6,15,22,23 \\
3,20,21 \\
5,13 \\
= \\
=\end{array}$ & $\begin{array}{l}3 \\
3 \\
1 \\
- \\
- \\
-\end{array}$ & $\begin{array}{c}15,22,23 \\
3,20,21 \\
13 \\
= \\
=\end{array}$ & $\begin{array}{l}1 \cdot 6 \\
4 \cdot 0 \\
1 \cdot 6 \\
= \\
= \\
=\end{array}$ & $\begin{array}{l}1 \\
1 \\
1 \\
= \\
-\end{array}$ & $\begin{array}{l}0.5 \\
1.3 \\
1 \cdot 6 \\
= \\
= \\
=\end{array}$ \\
\hline Total & 984 & & 11 & & $1 \cdot 1$ & 6 & 0.6 \\
\hline
\end{tabular}

Cases No. 1, 9, 12, 18 and 19 had left school by June 1, 1937.

Associated conditions. OBEsITY.- The first case is obviously an exception, and is quite different from the next three cases. His obesity was limited to the trunk; fat was noticeably absent from his face. Cases 2, 3, 4 had generalized obesity and small genitalia, and the testicle had not descended on either side when first seen ; but descent was complete in all cases at approximately the onset of puberty. In my opinion the right testicle in Case 3 would have descended spontaneously. If this contention is admitted, then the operation was doubly disadvantageous, because the testicle was misplaced.

Bilateral Non-Descent.-In addition to the first four cases, Cases 5 to 9 were affected bilaterally on the first examination ; in cases 5, 6, 7 descent at approximately puberty was spontaneous. In case 9 the left testicle descended when the patient was eleven years and three months, but the right was undescended at twelve and a half years, when puberty (which throughout this paper is judged by the appearance of pubic hairs) was starting. Unfortunately further follow-up has been impossible. The testicles of case 8 have failed to descend at sixteen and a half years and operation is being considered by his parents on the advice of his general practitioner. The remaining cases were unilateral, affecting the right in eleven instances, the left in three, and in one no note was made.

Anatomical Factors, Particularly the Presence of Coincident Hernia.-Cases 10 to 20 had no hernia, cases 2, 21, 22, 23, 24 each had a hernia on the same side as the undescended testicle. Descent took place spontaneously in cases $10,16,17,18,19$, and after hormone therapy and operation 
in cases 14 and 15 and not in cases $11,12,13$ or 20 . These have had neither hormone therapy nor operation. In the second group, descent has taken place only in case 2. A most interesting feature is the development of the hernia in case 22 at the age of puberty and the presence of the testicle in it, especially as recently Browne (1938) has stated on good evidence that 'a testicle that is in the inguinal canal cannot be felt through the skin.' In this case the testicle was thought to be in the inguinal canal before and after the appearance of the hernia. Spence (1938) has stated that in six of his patients who were subsequently operated on after unsuccessful hormone therapy, the testes which had been palpable through the skin prior to operation were found at operation to be lying in the inguinal canal. In fact, the operative finding in four of these six showed anatomical peculiarities which made it impossible for the testicle to emerge. Spence and Scowen (1935) noted that therapy with gonadotropic hormones caused a hernia to appear during treatment in five cases. They state : 'It seems highly probable that the hernia was present from the beginning and only became noticeable as the testes descended, the hernial sac presumably descending with the testis.' In the present small series it seems that a coincident hernia or a previous operation for one is the strongest factor militating against subsequent spontaneous descent of the testicle. Descent at puberty is highly improbable and surgeons, like Browne, who advise ' in every case operation, at which the co-existing hernia is removed,' are assuredly right.

Spontaneous descent.-Spontaneous descent took place $(a)$ in one bilateral case associated with pluriglandular disorder ; $(b)$ in two out of three bilateral cases associated with adiposity and on the left side of the third of these. $\mathrm{He}$ had had the right testicle surgically transposed in the scrotum. Descent coincided roughly with the onset of puberty ; $(c)$ in the other five bilateral cases, bilateral descent took place in three, on the right at the age of twelve and a half in one, and not in one ; $(d)$ in eleven unilateral ones unassociated with hernia, descent was spontaneous in five, was achieved by operation and hormone therapy in two, and in four others no change was noted ; and $(e)$ in five associated with hernia or previous operation for it, descent occurred in only one.

Spence and Scowen (1938), speaking of testicles which are examples of the ' superficial ectopic testis,' say skill is needed in the diagnosis of the condition, and after years of study have now been able to define the difference between a testicle lying in the inguinal canal and in the superficial inguinal position. Their criteria are :

(1) A superficial inguinal ectopic testis lies more superficially than one situated in the inguinal canal.

(2) When the testis is moved upwards and outwards in the direction of the canal, the superficial inguinal ectopic testis remains in the superficial position and becomes more obvious, whereas one situated in the canal will occupy a position deeper in the canal and thus will become less easily palpable.

(3) A testis situated in the canal cannot be moved towards the femoral region, whereas this may be possible in the superficial inguinal type.

(4) When a testis situated in the canal is moved downwards, it will travel in a direct path towards the neck of the scrotum, whereas one 
situated in the superficial inguinal region will tend to move slightly lateral to the neck of the scrotum.

My anatomical observations in the past have been chiefly concerned with eliminating the refractile testes from my cases. In future they will be directed along the lines advocated by Spence and Scowen. Yet my observations are highly suggestive that descent has occurred spontaneously at puberty in patients in whom the success would have been attributed to hormone therapy if they had received this treatment. Puberty is in all probability a time when there is an excess of gonadotropic hormones circulating in the blood, as evidenced by the mastitis of puberty in a small number of boys. If this is so, then physicians should develop patience and avoid hormone as well as surgical treatment, both of which are expensive luxuries. This statement is justified by the following facts : (1) A large proportion of testes descend spontaneously at puberty in all types of undescended testicles except those associated with hernia. (2) When descent does take place, the testicles, whether previously bilaterally or unilaterally undescended, develop normally. (3) That at or immediately after puberty, hormone therapy will probably be acting in alliance with an excess of natural hormones.

Armstrong's claim for thyroid extract as an aid to spontaneous descent must now be reconsidered. Dorff recognizes two distinct types of obesity associated with undescended testicles :

(1) Adiposogenital dystrophy thought to be due to hypogonadism characterized by adiposity, genital hypoplasia, eunuchoid proportions but normal osseous development.

(2) Masked hypothyroidism with retarded osseous development and hypoplastic testes, in addition to other symptoms of thyroid deficiency.

He has noted that after the exhibition of thyroid : (1) hypoplastic testes increase in size ; (2) undescended testes increase in size and descend to a lower point ; (3) the genitalia enlarge ; and (4) a more rapid response to treatment is noted near puberty.

Hardy (1938b) gave thyroid in connexion with gonadotropic hormone and concluded that it may have enhanced the effect of the gonadotropic principle for the obese patients, but that it seemed of no value to patients of normal build or to those of a feminine build. I have not noticed thyroid insufficiency in any of my cases, nor have I used thyroid except in the first case. Certainly intelligence is on the average well up to normal and in many instances decidedly above the normal. The question must be left sub judice.

\section{Summary}

Twenty-four boys with undescended testicles have been observed for from one to seven years. Spontaneous descent rarely occurs in those with associated herniae but does occur in a high proportion of the remaining nineteen at approximately puberty, whether the testicle is unilaterally or bilaterally undescended, and these testicles as judged by the usually accepted standards should be functionally perfect. No harm results from postponing operation 
or gonadotropic hormone therapy until puberty, at which time there is possibly an access of natural production of gonadotropic hormone in circulation. Grave coincident disorders-torsion, tumour or inflammation-have not been noted.

\section{REFERENCES}

Armstrong, H. G. (1918). Guy's Hosp. Gaz., 52, 271.

Bigler, J. A., Hardy, L. M., and Scott, H. V. (1938a). Amer. J. Dis. Child., 55, 100. (1938b). Loc. cit., 273.

Bjerre, H. (1937). Ugeskr. Laeg., 19, 513.

Browne, D. (1938). Brit. med. J., 2, 168.

Dorff, G. B. (1935). Amer. J. Dis. Child., 50, 649.

Drake, C. B. (1934). J. Amer. med. Ass., 102, 759.

Spence, A. W., and Scowen, E. F. (1935). Lancet, 2, 1,335. (1938). Ibid., 2, 983.

Turner, P. (1925). Guy's Hosp. Rep., 75, 209.

Williams, P. (1936). Lancet, 1, 426. 